\title{
Research on Online Training for University Faculties in the Web 2.0 Era
}

\author{
Xia Xu \\ Business College of Beijing Union University, Beijing, China \\ Email: xuxiajy0209@163.com
}

How to cite this paper: $\mathrm{Xu}, \mathrm{X}$. (2021). Research on Online Training for University Faculties in the Web 2.0 Era. Open Journal of Social Sciences, 9, 64-68.

https://doi.org/10.4236/jss.2021.96007

Received: May 10, 2021

Accepted: June 7, 2021

Published: June 10, 2021

Copyright $\odot 2021$ by author(s) and Scientific Research Publishing Inc. This work is licensed under the Creative Commons Attribution International License (CC BY 4.0).

http://creativecommons.org/licenses/by/4.0/

\begin{abstract}
Web 2.0 internet applications have provided more platforms for online training, and with the prevalence of mobile media, it is possible to learn anytime and anywhere. In this paper, we take business college of Beijing Union University as an example, through interviews, questionnaires and other forms, to understand the online training needs of university teachers. It also provides some strategies and suggestions to improve the effect of online training.
\end{abstract}

\section{Keywords}

Web 2.0, Universities and Colleges, Online, Training

\section{Introduction}

Web 2.0 APPs make use of interests as gathering points to form groups, and their platforms are open for users to share views anytime and anywhere. Information accumulates gradually on the internet and would never lose. In addition, the prevalence of mobile media has made learning anytime and anywhere increasingly popular among people (Web 2.0, https://baike.so.com/doc/7119987-7343121.html). Online training, is a kind of training organized by institutions or out of personal interests, using the internet as the information carrier and passing channel, and smart devices and mobile smart devices as human-computer interaction interface. Online training makes it possible to share excellent teaching resources and satisfy the learning habits and pace of different groups and individuals, but it requires a high level of self-discipline and learning ability. How to improve the effect of online training for college teachers is an urgent problem.

\section{The Current Situation of Our Faculty' Online Training}

To know the status of Chinese university faculties' training participation and their needs and current situation of online training, this article took 95 full-time 
teachers from Business College of Beijing Union University as subjects and samples, hoping to representatively show the current situation of university teachers' online training. In the 95 full-time teachers, for gender structure, there are 76 female teachers, accounting for $80 \%, 19$ male teachers, $20 \%$; for professional titles, there are 56 teachers with senior titles, accounting for $59 \%$, and 39 with intermediate titles, $41 \%$; among them, 65 are responsible for specialized courses and 30 for general courses. Ninety-five questionnaires were distributed, and all of them were returned and proved to be valid.

Statistics revealed that 86 teachers had participated in online training via the Internet before the outbreak of the COVID-19 pandemic, and all had online training during the outbreak. The pandemic enhanced reliance on online training. Among them, 76 teachers said that they were driven to attend training by college or university arrangement, that is, external momentum, while the rest were motivated by self-improvement and self-initiated participation, that is, internal momentum. Training organized by colleges or universities has recently focused on general knowledge for improving political science in courses, education and teaching skills, and scientific research ability, while the training that teachers take the initiative to participate in is mostly about foreign languages, research tools, in-depth research of a new field of knowledge and other methodological skills, which require long-term persistence and practical knowledge. As for professional titles, teachers with senior ones are less motivated to attend training than those with intermediate ones, and teachers who are about to be promoted are the most active in training. As for gender, female teachers take a higher initiative than male teachers. Reasons for choosing online training, as is generally believed, are as follows. Online training features rich resources, diversified forms and efficiency in manpower and resources, and enables teachers to use the fragmented time to learn more conveniently and to feel relaxed and comfortable during the training. Also, online training and face-to-face training achieve similar effects, while for improvements that require long-term persistence, like foreign languages, it is believed that independent online training with a high frequency and small steps is better than face-to-face training, but the difficulty lies in self-monitoring and perseverance. Teachers access online learning resources mainly through $\mathrm{MOOC}$, WeChat, various training websites and interactive platforms during the pandemic. Modes of online training include interactive or non-interactive online live, online record and play, and other APPs that contain rich learning resources. It is noticeable that female teachers, if not externally driven to participate in online live training, are more inclined to choose recording training, mainly because they can independently plan their learning schedule, their work and family education. A flexible learning schedule is the most important factor to online training ( $\mathrm{Zhu}$, Zhang, \& Gu, 2008).

From the questionnaire, it is obvious that teachers had already chosen to participate in some online training before the epidemic to improve their professional ability and foreign language skills. The current epidemic makes teachers organize online learning for students and conduct lectures online, which enhances 
their enthusiasm for online training. Through online training, teachers learn not only the knowledge taught but also the methods of teaching online in a practical way. They can see from the perspective of learners and find out how to better master the skills of online teaching. In the face of the sudden epidemic, the first thing for teachers to learn is how to be an anchor, and their participation can be experienced to improve their online teaching.

\section{Major Modes of Online Training for College Teachers}

The survey of Business College faculty shows that there are three popular modes of online training for university teachers.

\subsection{Synchronous Online Teaching Mode}

In this mode, teachers and students conduct interactions and have class at the same time but in different locations. The mode often makes use of live streaming software or applications to create virtual classrooms or meeting rooms to conduct one-to-one or one-to-many synchronous training. Software like Tencent Meeting, DingTalk and Zoom, can support multi-person video and audio communication, presentation, text seminar, etc. which are needed for synchronous lectures, and all can be displayed on multiple terminals such as tablets, cell phones, and computers. It features the different locations but the same time between trainers and trainees ( $\mathrm{Yu}, 2020)$.

It is suitable for the training requiring synchronous communications. It is relatively convenient for trainers and trainees to interact with each other, and trainees' questions can be solved in time. However, this mode requires a high level of independent learning ability. One-to-one training can solve problems in a targeted way while one-to-many can allow participants to see a problem from different perspectives and broaden the scope of communication, thus facilitating their thinking.

\subsection{Asynchronous Online Training Mode (Record \& Play Mode)}

Asynchronous Online Training Mode, also called Record \& Play Mode, means that trainers and trainees are at different times and places. Trainers first design teaching activities according to teaching objectives and then record videos. Trainees thus can watch those online videos or audios to finish their learning at their own pace and those videos can be watched repeatedly. However, the mode cannot provide trainees with learning supporting services and the learning effectiveness depends on trainees' self-control. Also, their questions and problems cannot get solved promptly. MOOC of Chinese Universities and various online course platforms adopt this mode.

\subsection{Self-Learning Mode Based on Tools}

In this mode, with the aid of some learning tools, learners conduct self-monitoring, self-guidance and self-improvement to show the role that self-efficacy and role 
modeling play in self-learning. Tools provide learners with learning resources, learning scaffolding and learning guidance to support learners' self-learning, help them to deal with learning content and construct their own knowledge system. In this process, learners have to self-determine clear objectives, their own learning tasks, choose corresponding learning strategies, conduct independent learning and exploration according to their own personality characteristics, and then evaluate and reflect on the results. Tools that university teachers often use include Engkoo, Tfish, a Chinese application to improve reading ability, and so on. Self-efficacy is one of the internal factors influencing self-learning, and teachers' requirements and partners' encouragement often help learners to establish a good sense of self-efficacy. External monitoring can be created by, for example, clocking in at WeChat, establishing WeChat groups, showing learning recording pictures at Moments, so as to push them to persist in learning (Liu, 2014).

\section{Suggestions for University Teachers to Participate in Online Training}

There are rules on how to improve the effectiveness of online teaching and learning, and only by grasping these rules or practices can online teaching become effective. The same applies to the university teachers who participate in the training. To improve their training effect, they also need to have a good command of the rules according to their characteristics and the modes of online training.

In general, for the training organized by colleges or universities, there are some points worth noticing in order to enhance the effectiveness of online training. First, try to ask teachers to bring their questions to the training. As is known to all, if participants are asked to learn a mere part of the content through online courses, which is almost no different from learners reading books by themselves, and there are no specific problems to solve or particular targets to accomplish, it is difficult to make learners' learning behavior happen effectively. In other words, the most conscious learners are just memorizing something. It is a low-level learning behavior, and the learning effect is really limited. The advantage of online learning is that it is problem-oriented rather than discipline-oriented, which also reflects the concept of learner-centered learning, a scientific philosophy that truly inspires students to pay attention, think, critique, and makes other learning behaviors happen.

Second, establish assessment goals. If in the online training, participants only need to browse the content casually to accomplish the learning task, it would be useless and a waste of learning resources and opportunities. "Work out accounts" is necessary. Organizers still need to set appropriate requirements and link the effectiveness of teachers' online learning with their access to follow-up training funding support and training opportunities. It is not to put pressure on teachers by examining, but to connect learning effect to training grades so as to 
inspire them to cherish training opportunities and strengthen learning motives. Undoubtedly, examination, as a drive for teachers' learning, is really needed.

For improvement-oriented training, it is recommended that teachers try to find cooperative learning partners, expand their horizons and listen to diverse viewpoints with the help of WeChat, $\mathrm{QQ}$, or other tools. They are allowed to showcase their learning achievements among their peers at the end of the training. If universities want to know the effectiveness of training, and participating teachers want to test their results, teachers can share and demonstrate what they have learned through teaching salons and teaching and research activities, which not only motivates the demonstrators' interest in learning, but also sets an example for other teachers to inspire and spur other teachers to learn and improve.

Online training will definitely be one of the indispensable training methods of career development for university teachers in the future. Teachers are believed to sum up more suitable learning modes in their continuous attempts, and universities will also find out more reasonable management modes to support teachers' development.

\section{Conclusion}

Based on the characteristics of online training in the era of Web2.0, this paper summarizes the online training mode of university faculties, which is represented by the teachers of business college, and gives some suggestions for improving the effect of online training.

\section{Conflicts of Interest}

The author declares no conflicts of interest regarding the publication of this paper.

\section{References}

Liu, M. (2014). Mobile Micro-Learning: A Practical Model for Adult Education. Adult Education, 3, 24-26.

Yu, S. (2020). Common Online Teaching Models and Tools. https://new.qq.com/omn/20200218/20200218A0CJO100.html

Zhou, D. (2019). Research on the Mobile Micro-learning Model for Highly Skilled Trainers-Taking WeChat as an Example. Human Resource Management and Talent Development, 11, 67-81.

Zhu, Z., Zhang, H., \& Gu, X. (2008). Micro Learning: A Practical Model of Informal Learning. China Educational Technology, 10-13. 